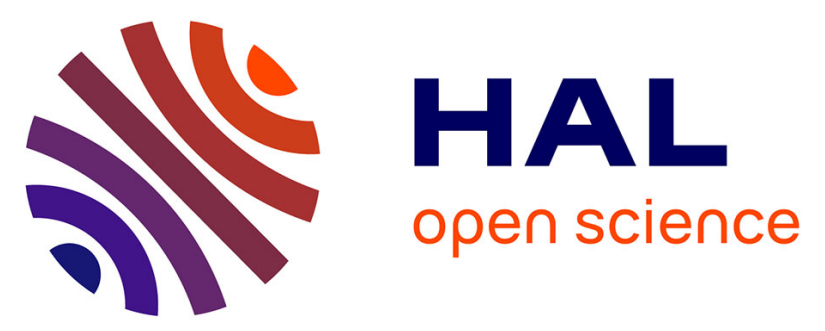

\title{
Temperature dependence of the particle/gas partition coefficient: An application to predict indoor gas-phase concentrations of semi-volatile organic compounds
}

Wenjuan Wei, Corinne Mandin, Olivier Blanchard, Fabien Mercier, Maud Pelletier, Barbara Le Bot, Philippe Glorennec, Olivier Ramalho

\section{To cite this version:}

Wenjuan Wei, Corinne Mandin, Olivier Blanchard, Fabien Mercier, Maud Pelletier, et al.. Temperature dependence of the particle/gas partition coefficient: An application to predict indoor gas-phase concentrations of semi-volatile organic compounds. Science of the Total Environment, 2016, 563-564, pp.506-512. 10.1016/j.scitotenv.2016.04.106 . hal-01313749

HAL Id: hal-01313749

https://hal-univ-rennes1.archives-ouvertes.fr/hal-01313749

Submitted on 8 Jul 2016

HAL is a multi-disciplinary open access archive for the deposit and dissemination of scientific research documents, whether they are published or not. The documents may come from teaching and research institutions in France or abroad, or from public or private research centers.
L'archive ouverte pluridisciplinaire HAL, est destinée au dépôt et à la diffusion de documents scientifiques de niveau recherche, publiés ou non, émanant des établissements d'enseignement et de recherche français ou étrangers, des laboratoires publics ou privés. 


\title{
Temperature dependence of the particle/gas partition coefficient: an
} application to predict indoor gas-phase concentrations of semi-volatile organic compounds

\author{
Wenjuan Wei ${ }^{a, *}$, Corinne Mandin ${ }^{\text {a,b,c }}$, Olivier Blanchard ${ }^{\text {d,b }}$, Fabien Mercier ${ }^{\text {d,c,b }}$, \\ Maud Pelletier d,b, Barbara Le Bot ${ }^{\mathrm{d}, \mathrm{c}, \mathrm{b}}$, Philippe Glorennec ${ }^{\mathrm{d}, \mathrm{b}}$, Olivier Ramalho ${ }^{\mathrm{a}}$
}

${ }^{\text {a }}$ University of Paris-Est, Scientific and Technical Center for Building (CSTB), Health and Comfort Department, French Indoor Air Quality Observatory (OQAI), 84 Avenue Jean Jaurès, Champs sur Marne, 77447 Marne la Vallée Cedex 2, France

${ }^{\mathrm{b}}$ INSERM-U1085, Irset-Research Institute for Environmental and Occupational Health, Rennes, France

${ }^{c}$ LERES-Environment and Health Research Laboratory (Irset and EHESP Technologic Platform), Rennes, France

${ }^{\mathrm{d}}$ EHESP-School of Public Health, Sorbonne Paris Cité, Rennes, France

*Corresponding author: Centre Scientifique et Technique du Bâtiment (CSTB), Direction SantéConfort - Observatoire de la Qualité de l'Air Intérieur (OQAI), 84 Avenue Jean Jaurès, Champs sur Marne, 77447 Marne la Vallée Cedex 2, France. Tel.: +331 6468 8457; fax: +331 64688823. E-mail address: Wenjuan.Wei@cstb.fr 


\begin{abstract}
The indoor gas-phase concentrations of semi-volatile organic compounds (SVOCs) can be predicted from their respective concentrations in airborne particles by applying the particle/gas partitioning equilibrium. The temperature used for partitioning is often set to $25^{\circ} \mathrm{C}$. However, indoor temperatures frequently differ from this reference value. This assumption may result in errors in the predicted equilibrium gas-phase SVOC concentrations. To improve the prediction model, the temperature dependence of the particle/gas partition coefficient must be addressed. In this paper, a theoretical relationship between the particle/gas partition coefficient and temperature was developed based on the SVOC absorptive mechanism. The SVOC particle/gas partition coefficients predicted by employing the derived theoretical relationship agree well with the experimental data retrieved from the literature $(R>0.93)$. The influence of temperature on the equilibrium gas-phase SVOC concentration was quantified by a dimensionless analysis of the derived relationship between the SVOC particle/gas partition coefficient and temperature. The predicted equilibrium gas-phase SVOC concentration decreased by between $31 \%$ and $53 \%$ when the temperature was lowered by $6{ }^{\circ} \mathrm{C}$, while it increased by up to $750 \%$ when the indoor temperature increased from $15^{\circ} \mathrm{C}$ to $30^{\circ} \mathrm{C}$.
\end{abstract}

\title{
Key words
}

SVOCs, partitioning, equilibrium, indoor air quality 


\section{Introduction}

Most semi-volatile organic compounds (SVOCs), such as phthalates and polybrominated diphenyl ethers (PBDEs), have widespread consumer use and environmental occurrence, and some are suspected to be neurotoxic or endocrine-disrupting chemicals (Rudel et al., 2003; Salapasidou et al., 2011; Blanchard et al., 2014; Fournier et al., 2014; Bamai et al., 2014; Dodson et al., 2015). SVOCs in indoor environments appear in the gas-phase, on airborne particles and in dust settled on floors and other surfaces (Weschler and Nazaroff, 2008). If the gas-phase SVOC concentrations in an indoor environment have not been measured, they can be predicted from the measured concentrations in another phase. Unknown gas-phase SVOC concentrations may be predicted from the measured SVOC concentrations in airborne particles or settled dust, assuming that the partition equilibrium is reached between the different phases (Weschler et al., 2009). The partitioning of SVOCs between airborne organic particles and the gas-phase at equilibrium is characterized by the SVOC particle/gas partition coefficient, $K_{\mathrm{p}}$, which can be estimated with the saturation vapor pressure of the pure sub-cooled liquid, $p_{\mathrm{L}}^{0}$, and the octanol/air partition coefficient, $K_{\mathrm{OA}}$ (Weschler et al., 2009). The $K_{\mathrm{p}}$ value is needed to predict the unknown gasphase SVOC concentration from its measured concentration in airborne particles. $K_{\mathrm{p}}$ values can be retrieved from the literature for a limited number of SVOCs and must be calculated from the $K_{\mathrm{OA}}$ or $p_{\mathrm{L}}^{0}$ values for the many SVOCs for which no values have been measured. Moreover $K_{\mathrm{p}}$ depends on temperature (Pankow, 1987).

Adsorption/desorption and absorption/desorption between the gas-phase and airborne particles constitute the two partitioning mechanisms for organic compounds. Previous studies show that the structure of a suspended airborne particle can be described as either a solid core covered by a 
SVOC liquid film or a porous material in which the pores are filled with SVOC liquid (Husar and Shu, 1975; Ancelet et al., 2011; Liu et al., 2013). Therefore, absorption/desorption may be dominant for SVOCs with low volatility.

In previous studies, the adsorptive models of the particle/gas partitioning mechanism for organic compounds have assumed physical adsorption and desorption of organic compounds between the gas-phase and airborne particles (Pankow, 1987). Thus, a theoretical linear relationship can be described between $\log _{10} K_{\mathrm{p}}$ and $T^{-1}$ (Pankow, 1987, Boethling and Mackay, 2000; FinlaysonPitts and Pitts, 2000; Schwarzenbach et al., 2003; Seinfeld and Pandis, 2006) and between $\log _{10} K_{\mathrm{OA}}$ and $T^{-1}$ ( $T$ in degrees Kelvin) (Harner and Mackay, 1995) for organic compounds. Empirical relationships have also been established based on regressions of the experimental data of $\log _{10} K_{\mathrm{p}}$ and $T^{-1}$ for dioxins and furans, polychlorinated biphenyls (PCBs), polychlorinated naphthalenes (PCNs), and polycyclic aromatic hydrocarbons (PAHs) (Kaupp and McLachlan, 1999). In addition, several studies have addressed the empirical relationships between $\log _{10} K_{\mathrm{OA}}$ and $T^{-1}$ for some chlorobenzenes (Harner and Mackay, 1995; Shoeib and Harner, 2002; Li et al., 2006), methylsiloxanes (Xu and Kropscott, 2013), PCNs (Li et al., 2006), pesticides (Harner and Mackay, 1995; Shoeib and Harner, 2002; Li et al., 2006; Odabasi and Cetin, 2012), PAHs (Li et al., 2006; Harner and Bidleman, 1998; Odabasi et al., 2006a,b; He and Balasubramanian, 2009), PCBs (Harner and Mackay, 1995; Li et al., 2006; He and Balasubramanian, 2009; Harner and Bidleman, 1996), and PBDEs (Li et al., 2006; Chen et al., 2003).

However, considering the absorption mechanism, the theoretical equations between $K_{\mathrm{p}}$ and $p_{\mathrm{L}}^{0}$ or $K_{\text {oa }}$, which were determined by Pankow (1994) and Finizio et al. (1997), respectively, consist of temperature-independent constants and temperature-dependent parameters, e.g., $K_{\text {oa }}$. Thus, the 
temperature impact on $K_{\mathrm{p}}$ is associated with the temperature impact on $K_{\mathrm{oa}}$. One limitation in the calculation of the theoretical equations is that some of the physical parameters of the equations, e.g., the activity coefficient of the absorbing SVOCs in airborne particles, have not been fully studied for most SVOCs at different temperatures and their values remain assumed in the calculation (Harner, 1998; Weschler and Nazaroff, 2010). The empirical relationships between $K_{\mathrm{p}}, K_{\mathrm{OA}}$ or $p_{\mathrm{L}}^{0}$ in the literature, which are based on regressions of experimental data, were generally obtained at a reference temperature, e.g., $25^{\circ} \mathrm{C}$ (Finizio et al., 1997; Naumova et al., 2003). No previous study has indicated whether the regression constants in the empirical equations obtained at a reference temperature can be applied to other temperature values. Because the theoretical relationship between $K_{\mathrm{p}}$ and temperature based on the absorptive mechanism has not been fully studied, the difference between the real indoor temperature and the temperature used in the literature for developing the empirical equation may lead to errors in the predicted gas-phase SVOC concentrations.

The objectives of this study were to (1) develop a theoretical relationship between the particle/gas absorptive partition coefficient and temperature for SVOCs and (2) quantitatively analyze the extent to which the indoor temperature influences the precision of the predicted SVOC concentrations in the gas-phase from the concentrations in the airborne particles.

\section{Material and methods}

\subsection{Theoretical derivation}

The equilibrium gas-phase SVOC concentration is defined by 


$$
C_{\mathrm{g}}=\frac{F / T S P}{K_{\mathrm{p}}}
$$

where $F\left(\mathrm{ng} / \mathrm{m}^{3}\right)$ and $C_{\mathrm{g}}\left(\mathrm{ng} / \mathrm{m}^{3}\right)$ are the equilibrium concentrations of SVOCs in the airborne particles and in the gas-phase, respectively, $\operatorname{TSP}\left(\mu \mathrm{g} / \mathrm{m}^{3}\right)$ is the total concentration of suspended airborne particles, and $K_{\mathrm{p}}$ is the particle/gas partition coefficient $\left(\mathrm{m}^{3} / \mu \mathrm{g}\right)$.

According to the absorptive mechanism for SVOCs, Pankow derived the following particle/gas partition coefficient $K_{\mathrm{p}}\left(\mathrm{m}^{3} / \mu \mathrm{g}\right)$ (Pankow, 1994):

$$
K_{\mathrm{p}}=\frac{f_{\mathrm{om}} R T}{M W_{\mathrm{om}} \alpha p_{\mathrm{L}, T}^{0} 10^{6}}
$$

where $f_{\text {om }}$ is the weight fraction of the airborne particles absorbing organic materials; $R$ (8.314 $\mathrm{J} /(\mathrm{mol} \mathrm{K}))$ is the gas constant; $T(\mathrm{~K})$ is the temperature, $M W_{\mathrm{om}}(\mathrm{g} / \mathrm{mol})$ is the mean molecular weight of the absorbing organic material; $\alpha$ is the activity coefficient of the compound in the organic material phase; and $p_{\mathrm{L}, T}^{0}(\mathrm{~Pa})$ is the saturation vapor pressure of the pure sub-cooled liquid compound at a temperature $T$.

The phase transition of a single constituent between the liquid phase and the gas-phase can be characterized by the Clausius-Clapeyron relationship:

$$
\frac{\mathrm{d} p_{\mathrm{L}, T}^{0}}{\mathrm{~d} T}=\frac{\Delta H}{T \Delta V}
$$

where $\Delta H(\mathrm{~J} / \mathrm{mol})$ is the phase change enthalpy; and $\Delta V\left(\mathrm{~m}^{3} / \mathrm{mol}\right)$ is the change in the volume of the constituent during the phase change. The phase change enthalpies for SVOCs can be retrieved from the literature (Acree and Chickos, 2010). 
We assume that (1) the change in the SVOC volume in the liquid phase is negligible compared to the change in the gas-phase, (2) the gas-phase containing SVOCs is an ideal gas, and (3) the variation in the phase change enthalpy for SVOCs is negligible at room temperature, as shown in Acree and Chickos (2010) for many SVOCs. Thus, the change in the volume of the SVOC during the phase change can be expressed as

$$
\Delta V=\frac{R T}{p_{\mathrm{L}, T}^{0}}
$$

Combining Eqs. (3) and (4), we have

$$
\frac{\mathrm{d} p_{\mathrm{L}, T}^{0}}{\mathrm{~d} T}=\frac{p_{\mathrm{L}, T}^{0} \Delta H}{T^{2} R}
$$

Thus,

$$
\frac{p_{\mathrm{L}, 2}^{0}}{p_{\mathrm{L}, 1}^{0}}=e^{\frac{\Delta H}{R}\left(\frac{1}{T_{1}}-\frac{1}{T_{2}}\right)}
$$

Assuming that the variation in the activity coefficient of SVOCs in the airborne particles is negligible for varying room temperatures, Eqs. (2) and (6) can be combined to obtain a relationship between the particle/gas absorptive partitioning coefficient and temperature for SVOCs:

$$
\begin{gathered}
K_{\mathrm{p} 2}=K_{\mathrm{p} 1} \frac{T_{2}}{T_{1}} e^{\frac{\Delta H}{R}\left(\frac{1}{T_{2}}-\frac{1}{T_{1}}\right)} \\
\log _{10} K_{\mathrm{p} 2}=\frac{\Delta H}{2.303 R}\left(\frac{1}{T_{2}}-\frac{1}{T_{1}}\right)+\log _{10} \frac{T_{2}}{T_{1}}+\log _{10} K_{\mathrm{p} 1}
\end{gathered}
$$


Eqs. (7) and (8) indicate that if a reference particle/gas partition coefficient $\left(K_{\mathrm{p} 1}\right)$ associated with a reference temperature $\left(T_{1}\right)$ is known for a given SVOC, the particle/gas partition coefficient $\left(K_{\mathrm{p} 2}\right)$ at the indoor temperature $\left(T_{2}\right)$ can be predicted for that SVOC. Therefore, the accuracy of the predicted $K_{\mathrm{p} 2}$ is associated with the accuracy of the measured temperature and the reference $K_{\mathrm{p} 1}$ (measured or predicted). Eqs. (7) and (8) allow $K_{\mathrm{p}}$ to be extrapolated from the room temperature in a previous study to the room temperature of interest.

According to Eq. (8), $\log _{10} K_{\mathrm{p}, \mathrm{T}}$ is a function of temperature varying with $\Delta H /(2.303 R T)$ and $\log _{10} T$. We define

$$
\begin{gathered}
f(T)=\frac{\log _{10} \frac{T_{2}}{T_{1}}}{\frac{1}{T_{2}}-\frac{1}{T_{1}}} \\
f(\Delta H)=\frac{\Delta H}{2.303 R}
\end{gathered}
$$

If $|f(T)| \ll|f(\Delta H)|$, then $f(T)$ is negligible compared to $f(\Delta H)$. This indicates that when the temperature varies over a small range and $\Delta H$ is high, Eq. (8) can be simplified to

$$
\frac{\log _{10} K_{\mathrm{p} 2}-\log _{10} K_{\mathrm{p} 1}}{\frac{1}{T_{2}}-\frac{1}{T_{1}}} \approx \frac{\Delta H}{2.303 R}
$$

Thus,

$$
\log _{10} K_{\mathrm{p}, \mathrm{T}}=\frac{A}{T}+\mathrm{B}
$$


where $A \approx \Delta H /(2.303 R)$ and $B$ is a constant that varies among SVOCs. Eq. (12) is the theoretical relationship between $K_{\mathrm{p}}$ and temperature based on the adsorptive mechanism (Schwarzenbach et al., 2003). Some phthalates were investigated as examples in the present study to quantitatively analyze the errors associated with this assumption and simplification.

\subsection{Validation of the derived relationship with experimental data}

Kaupp and McLachlan (1999) measured the concentration of total suspended airborne particles, $T S P$, and the SVOC concentrations in both the gas-phase and airborne particles for temperatures ranging from $0.2{ }^{\circ} \mathrm{C}$ to $20.4{ }^{\circ} \mathrm{C}$. The experimental $K_{\mathrm{p}}$ values in their study for PCNs $(n=4)$, PCBs $(n=3)$, dioxins and furans $(n=3)$, and PAHs $(n=3)$ for a range of temperatures were calculated in the present study using Eq. (1) and then compared with the predicted values obtained by applying Eq. (7) under the assumption that the $K_{\mathrm{p}}$ values measured at the median temperature $\left(12.4{ }^{\circ} \mathrm{C}\right)$ were used as the reference value. It should be noted that the TSP value in the experiment was not associated with a specific particle size. Thus, the $K_{\mathrm{p}}$ value calculated with Eq. (1) is equivalent to the value estimated from all of the particles of equivalent size in the measurement.

Because there are few studies in the literature that report measurements of SVOC $K_{\mathrm{p}}$ under different temperatures, we used indirect values (i.e., observed $K_{\mathrm{p}}$ values). The observed $K_{\mathrm{p}}$ values were obtained from the measurement of $K_{\mathrm{OA}}$ and calculated using the linear relationship between $K_{\mathrm{p}}$ and $K_{\mathrm{OA}}($ Weschler and Nazaroff, 2010):

$$
K_{\mathrm{p}}=\frac{f_{\mathrm{om}} K_{\mathrm{OA}}}{\rho_{\mathrm{p}}}
$$


where $f_{\text {om }}$ is assumed to be constant in an indoor environment with a value of 0.4 for SVOCs and $\rho_{\mathrm{p}}\left(=1 \times 10^{6} \mathrm{~g} / \mathrm{m}^{3}\right)$ is the density of the airborne particles (Weschler and Nazaroff, 2010). Eq. (13) was selected over other equations for the validation of Eq. (7) because it was not established based on a reference temperature. Although $f_{\text {om }}$ and $\rho_{\mathrm{p}}$ may depend on the temperature, indoor environment, and nature of the particles, and may vary across SVOC classes, the assumed values proposed by Weschler and Nazaroff (2010) were applied in this study. Many measurements of $K_{\mathrm{OA}}$ values under various temperature conditions are available in the literature for PCNs $(n=7)$, PCBs $(n=12)$, dioxins and furans $(n=5)$, PBDEs $(n=4)$, and PAHs $(n=4)$ (Li et al., 2006). The observed $K_{\mathrm{p}}$ values were calculated from the measured $K_{\mathrm{OA}}$ values under various temperatures using Eq. (13). The predicted $K_{\mathrm{p}}$ values under various temperatures were calculated from Eq. (7) assuming the observed $K_{\mathrm{p}}$ at $25^{\circ} \mathrm{C}$ as the reference value. The observed and predicted $K_{\mathrm{p}}$ values were then compared.

For phthalates, the $K_{\mathrm{p}}$ and $K_{\mathrm{OA}}$ values for a range of temperatures have rarely been measured. Benning et al. (2013) used a stainless steel chamber to measure $K_{\mathrm{p}}$ for di-(2-ethylhexyl)phthalate (DEHP) at $22.0 \pm 0.3{ }^{\circ} \mathrm{C}$ with vinyl flooring as the DEHP source, resulting in a $K_{\mathrm{p}}$ value of $0.032 \pm 0.003 \mathrm{~m}^{3} / \mu \mathrm{g}$. To study the temperature dependence of $K_{\mathrm{p}}$ for DEHP, $K_{\mathrm{p}}$ values for a range of temperatures were predicted using Eq. (7), using a reference temperature of $22.0{ }^{\circ} \mathrm{C}$ for the measured $K_{\mathrm{p}}$ value.

For other phthalates, e.g., di-n-butyl phthalate (DnBP), diisobutyl phthalate (DiBP), diisononyl phthalate (DiNP), benzyl butyl phthalate (BBzP), diethyl phthalate (DEP), and dimethyl phthalate (DMP), the experimental determination of $K_{\mathrm{p}}$ over a range of temperatures has never been studied. For these compounds, $K_{\mathrm{p}}$ values were calculated from the $K_{\mathrm{OA}}$ values at $25{ }^{\circ} \mathrm{C}$ 
using Eq. (13). The $K_{\mathrm{OA}}$ values used for calculating $K_{\mathrm{p}}$ were obtained using EPI Suite v4.11 software, which was developed by the U.S. Environmental Protection Agency (U.S. EPA). The $K_{\mathrm{OA}}$ values were estimated from octanol/water partition coefficients using the KOAWIN calculator in the EPI Suite software. The $K_{\mathrm{p}}$ values calculated at $25{ }^{\circ} \mathrm{C}$ were used as the reference values, and the values at other temperatures were predicted using Eq. (7).

\subsection{Temperature dependence of the predicted gas-phase SVOC concentrations}

The relationship between $K_{\mathrm{p}}$ and temperature can be applied to both indoor and outdoor environments. It was applied to an indoor environment in the present study. An unknown equilibrium gas-phase SVOC concentration in an indoor environment can be predicted using Eq.

(1) if both the SVOC concentration in the airborne particles, $F$, and the total concentration of suspended airborne particles, TSP, are measured. The indoor temperature is the key parameter that influences the determined $K_{\mathrm{p}}$ value and the predicted SVOC concentration in the gas-phase. The temperature influence on the predicted SVOC concentration in the gas-phase varies among previous studies. However, a universal temperature dependence law for the prediction of gasphase SVOC concentrations can be quantified by a dimensionless analysis applicable to any SVOC regardless of the measured concentration of $F$ or TSP. Considering that $K_{\mathrm{p}}$ values decrease and $C_{\mathrm{g}}$ values increase with increasing temperature (Kaupp and McLachlan, 1999), we defined the dimensionless temperature, $T^{*}$, and the dimensionless gas-phase SVOC concentration, $C_{\mathrm{g}}^{*}$, as

$$
T^{*}=\frac{T}{T_{\mathrm{e}}}
$$




$$
C_{\mathrm{g}}^{*}=\frac{C_{\mathrm{g}}}{C_{\mathrm{g} \mid T=T_{\mathrm{e}}}}
$$

where $T_{\mathrm{e}}(\mathrm{K})$ is the assumed highest temperature in a common indoor environment; and $C_{\mathrm{g} \mid T=T_{\mathrm{e}}}$ $\left(\mathrm{ng} / \mathrm{m}^{3}\right)$ is the gas-phase SVOC concentration at a temperature $T_{\mathrm{e}}$. Thus, $0 \leq T^{*} \leq 1$ and $0 \leq$ $C_{\mathrm{g}}^{*} \leq 1$

Combining Eqs. (1), (7), (14), and (15), we obtain a dimensionless relationship between $C_{\mathrm{g}}^{*}$ and $T^{*}$ for any SVOC:

$$
C_{\mathrm{g}}^{*}=\frac{K_{\mathrm{p} \mid T=T_{\mathrm{e}}}}{K_{\mathrm{p}}}=\frac{10^{\Delta H^{*}\left(1-\frac{1}{T^{*}}\right)}}{T^{*}}
$$

where $\Delta H^{*}=\Delta H /\left(2.303 R T_{\mathrm{e}}\right)$. Eq. (16) provides a dimensionless gas-phase SVOC concentration associated with a dimensionless temperature, regardless of the measured $F$ or TSP values. The assumed $T_{\mathrm{e}}$ value has a negligible influence on the predicted $C_{\mathrm{g}}^{*}$ value when it lies between $10{ }^{\circ} \mathrm{C}$ and $50{ }^{\circ} \mathrm{C}$ (Fig. 1). In the present study, we assumed $50{ }^{\circ} \mathrm{C}$ as the highest temperature in an indoor environment.

Fig. 1. Influence of the assumed $T_{\mathrm{e}}$ on the predicted value of $C_{\mathrm{g}}^{*}$

\section{Results and discussion}

3.1. Comparison of the predicted and measured $K_{\mathrm{p}}$ values 
The predicted and measured $K_{\mathrm{p}}$ values for PCNs, PCBs, dioxins and furans, and PAHs (Kaupp and McLachlan, 1999) are compared in Fig. 2. The temperature for the measurements ranged between $0.2{ }^{\circ} \mathrm{C}$ and $20.4{ }^{\circ} \mathrm{C}$, although measurement at $12.4{ }^{\circ} \mathrm{C}$ was performed for all of the studied compounds. Therefore, we used $12.4^{\circ} \mathrm{C}$ as the reference temperature. The predicted and measured $K_{\mathrm{p}}$ values for a range of temperatures are well correlated in most cases. The determination coefficient, $R^{2}$, for tetrachloronaphthalene and 2,3,7,8-tetrachlorodibenzofuran is 0.87 and 0.92, respectively, whereas the $R^{2}$ values for the other PCNs, PCBs and dioxins all exceed 0.95. The $R^{2}$ values for PAHs range from 0.68 to 0.78 (Fig. 2(d)). The difference between the predicted and measured values can vary up to $50 \%$ for some PAHs. This variation may be due to the scatter of the experimental data, as apparent in Fig. 2(d). Nevertheless, the comparison shows the consistency between the measured and predicted $K_{\mathrm{p}}$ values over a range of temperatures for the 13 studied SVOCs.

Fig. 2. Comparison of the predicted and measured values of $\log _{10} K_{\mathrm{p}}$ at various temperatures.

Additional comparisons between the predicted and observed $K_{\mathrm{p}}$ values are presented in Table 1. The predicted $K_{\mathrm{p}}$ values were calculated using Eq. (13), employing the $K_{\mathrm{OA}}$ values measured at $25^{\circ} \mathrm{C}$ from the literature (Li et al., 2006) as reference values; then, $K_{\mathrm{p}}$ was predicted at various temperatures using Eq. (7). The observed $K_{\mathrm{p}}$ values at different temperatures were calculated using Eq. (13), employing the $K_{\mathrm{OA}}$ values from the literature (Li et al., 2006). A high correlation $\left(R^{2}>0.95\right)$ was found for all of the PCNs, PCBs, dioxins and furans, PBDEs, and PAHs ( $n=32$ in total). 
Table 1. Comparison of the predicted and observed values of $K_{\mathrm{p}}$.

3.2. Estimates of $K_{\mathrm{p}}$ at different temperatures for phthalates

Experimental $K_{\mathrm{p}}$ and $K_{\mathrm{OA}}$ values as a function of temperature are scarce for phthalates. Because the $K_{\mathrm{p}}$ values are consistent between the predicted and both the measured values and the observed values obtained from $K_{\mathrm{OA}}$ for several PCNs, PCBs, dioxins and furans, PBDEs, and PAHs over a range of temperatures, we assumed that the temperature influence on the $K_{\mathrm{p}}$ values for phthalates can be predicted via Eq. (7).

Fig. 3 shows the simulation of $|f(T) / f(\Delta H)|$ for different temperatures and phase change enthalpies. Between $0{ }^{\circ} \mathrm{C}$ and $50{ }^{\circ} \mathrm{C},|f(T) / f(\Delta H)|<5 \%$ for $\Delta H>50 \mathrm{~kJ} / \mathrm{mol}$ and $\mid f(T) /$ $f(\Delta H) \mid<3 \%$ for $\Delta H>100 \mathrm{~kJ} / \mathrm{mol}$. Because the phase change enthalpies of the phthalates DEHP, DnBP, DiBP, DiNP, BBzP, DEP, and DMP all exceed $5 \times 10^{4} \mathrm{~J} / \mathrm{mol}$ (Acree and Chickos, 2010), simplifying Eq. (7) to Eq. (12) results in less than $5 \%$ error in $\left|\log _{10} K_{\mathrm{p} 2}-\log _{10} K_{\mathrm{p} 1}\right|$.

The $K_{\mathrm{p}}$ values for these 7 target phthalates at different temperatures predicted using Eq. (7) are regressed using Eq. (12) (Fig. 4). The $R^{2}$ values for the regression of the target phthalates exceed 0.99. The regression slopes and the intercepts, which indicate the empirical $A$ and $B$ values in Eq. (12), for the target phthalates range from 3,764 to 5,808 and from -20.16 to -18.29 , respectively.

Fig. 3. $|f(T) / f(\Delta H)|$ at different temperatures and phase change enthalpies.

Fig. 4. $K_{\mathrm{p}}$ for phthalates. 
3.3. Impact of temperature on the predicted gas-phase SVOC concentrations

The predicted equilibrium gas-phase SVOC concentrations are very sensitive to temperature (Fig. 5). For all of the examined SVOCs with a phase change enthalpy between $50 \mathrm{~kJ} / \mathrm{mol}$ and $100 \mathrm{~kJ} / \mathrm{mol}$, the equilibrium gas-phase SVOC concentration decreased between $31 \%$ and $53 \%$ for a decrease of $2 \%$ in the dimensionless temperature (namely, $6 \mathrm{~K}$ ). This finding indicates that the temperature is critical for determining accurate $K_{\mathrm{p}}$ values and thus accurately predicting the gasphase SVOC concentrations. When the indoor temperature is lower than the reference temperature used for determining $K_{\mathrm{p}}$, the predicted gas-phase SVOC concentrations may be significantly overestimated. However, when the temperature is higher than the reference temperature, $C_{\mathrm{g}}$ may be underestimated. The equilibrium gas-phase SVOC concentrations were found to increase by as much as $750 \%$ due to increasing the indoor temperature from $15{ }^{\circ} \mathrm{C}$ to $30{ }^{\circ} \mathrm{C}$ (Table $\mathrm{S} 1$ in the supplementary material).

Fig. 5. Temperature dependence of the dimensionless gas-phase SVOC concentration.

\subsection{Limitations of the study}

Some assumptions made for the derivation of the theoretical relation between $K_{\mathrm{p}}$ and temperature may restrict the application of the derived relation. First, absorption was assumed to be the dominant mechanism for SVOC gas/particle partitioning. However, as discussed by Lohmann and Lammel (2004), both adsorptive and absorptive mechanisms may contribute to the gas/particle partitioning for some SVOCs, e.g., PAHs. As a result, the volatility of SVOCs needs 
to be taken into account when applying the equations proposed by Pankow (1987) or studied in the present paper. The Eqs. (7) and (8) proposed in this study may be appropriate for modeling SVOCs of low volatility due to the absorption assumption, whereas the equations proposed by Pankow (1987) may be appropriate for modeling compounds of high volatility due to the adsorption assumption. Second, the airborne particles were assumed to be porous materials. This assumption may not be true in some mining areas and locations near oceans, where the airborne particles are mainly composed of mineral crystals. In addition, in some extreme environments, the indoor temperature may be below $0{ }^{\circ} \mathrm{C}$, while the relative humidity may be close to saturation, resulting in condensation and freezing of water vapor on the airborne particles. However, Eq. (2) developed by Pankow (1994) to describe the absorptive partitioning is independent from the morphology of particles. Third, possible chemical reactions between SVOCs on the airborne particles were not considered in the present study. Therefore, the derived equation is not applicable if chemical reaction occurs. Fourth, the variation in the activity coefficient for SVOCs in the airborne particles was assumed to be negligible for the studied range of temperatures. This assumption was applied due to a lack of studies on the activity coefficients of SVOCs. Measurements showed that the activity coefficients of some hydrocarbons generally decreased by less than $5 \%$ with increasing temperature from $9{ }^{\circ} \mathrm{C}$ to 35 ${ }^{\circ} \mathrm{C}$ (Won, 1989). Moreover, when the temperature increased from $25^{\circ} \mathrm{C}$ to $35^{\circ} \mathrm{C}$, the activity coefficients of methanol and toluene decrease by $2 \%$ and $7 \%$, respectively, at infinite dilution in ionic liquid (Domanska and Paduszynski, 2010). The activity coefficient of a compound, e.g., SVOC, can be calculated using thermodynamic models such as the universal functional-group activity coefficient (UNIFAC) model (Fredenslund et al., 1975; Jang and Kamens, 1998). The calculation of the activity coefficient using the UNIFAC model shows that the variation of the 
activity coefficient, $\alpha$, of a compound is related to its partial molar excess enthalpy at infinite dilution, $H$ (Coutinho et al., 1995), which generally ranges between $-1 \mathrm{~kJ} / \mathrm{mol}$ and $5 \mathrm{~kJ} / \mathrm{mol}$ (Kato and Gmehling, 2005). The $\alpha$ varies between $1 \%$ and $7 \%$ when the temperature varies by $10{ }^{\circ} \mathrm{C}$ (Fig. S1 in the supplementary material). Eqs. (7) and (8) were only validated under room temperature in the present study. Last, the dimensionless model can be used to predict the gasphase SVOC concentration at equilibrium partitioning when the indoor air is well mixed. For SVOCs, the time to reach equilibrium partitioning between gas-phase and airborne particles varies between seconds to days depending on the volatility of the SVOCs and the diameter of the particle (Weschler and Nazaroff, 2008). The dimensionless model in the present study has the advantage of providing rapid estimates for a large dataset, such as a nationwide sample. However, it cannot be used to address the dynamic mass transfer process of SVOCs.

\section{Conclusions}

A theoretical relationship between the particle/gas partition coefficient and temperature was developed for SVOCs based on the absorptive mechanism. This equation does not require the input of $K_{\mathrm{OA}}$ or $p_{\mathrm{L}}^{0}$. The $K_{\mathrm{p}}$ values at indoor temperatures can be predicted using the derived relation if $K_{\mathrm{p}}$ values at a reference temperature are available (measured or predicted). The derived relationship agrees well with the experimental results from studies on the temperature dependence of $K_{\mathrm{p}}$ in the literature. Both theoretical and experimental materials show a strong influence of temperature on $K_{\mathrm{p}}$ and the prediction of $C_{\mathrm{g}}$ from $F$. One equation is now available to account for this dependency and to estimate both $K_{\mathrm{p}}$ and $C_{\mathrm{g}}$. 


\section{Acknowledgments}

The ECOS project was supported by the French Scientific Program on Endocrine Disruptors (PNRPE; Grant n²100522667), the French Agency for Food, Environmental and Occupational Health and Safety (ANSES; Grant n²011-1-128), the French Observatory of Indoor Air Quality (OQAI; Grants 2011 and 2012), the Scientific and Technical Building Centre (CSTB), and the School of Public Health (EHESP).

The preparation of this manuscript was performed during a scientific visit to CSTB (WW) and was supported by a grant from the "Carnot Programme" (Grant 2011).

\section{References}

Ancelet, T., Davy, P. K., Trompetter, W. J., Markwitz, A., Weatherburn, D. C., 2011. Carbonaceous aerosols in an urban tunnel. Atmos. Environ., 45 (26), 4463-4469.

Acree, W., Chickos, J.S., 2010. Phase transition enthalpy measurements of organic and organometallic compounds: sublimation, vaporization and fusion enthalpies from 1880 to 2010. J. Phys. Chem. Ref. Data 39 (4), 1-942.

Bamai, Y. A., Shibata, E., Saito, I., Araki, A., Kanazawa, A., Morimoto, K., Nakayama, K., Tanaka, M., Takigawa, T., Yoshimura, T., Chikara, H., Saijo, Y., Kishi R., 2014. Exposure to house dust phthalates in relation to asthma and allergies in both children and adults. Sci. Total Environ. 485-486, 153-163. 
Benning, J. L., Liu, Z., Tiwari, A., Little, J. C., Marr, L. C., 2013. Characterizing gas-particle interactions of phthalate plasticizer emitted from vinyl flooring. Environ. Sci. Technol. 47 (6), 2696-2703.

Blanchard, O., Glorennec, P., Mercier, F., Bonvallot, N., Chevrier, C., Ramalho, O., Mandin, C., Le Bot, B., 2014. Semivolatile organic compounds in indoor air and settled dust in 30 French dwellings. Environ. Sci. Technol. 48 (7), 3959-3969.

Boethling, R. S., Mackay, D. Handbook of property estimation methods for chemicals: environmental and health sciences. Boca Raton: Lewis Publishers; 2000.

Chen, J. W., Harner, T., Yang, P., Quan, X., Chen, S., Schramm, K. W., Kettrup, A., 2003. Quantitative predictive models for octanol-air partition coefficients of polybrominated diphenyl ethers at different temperatures. Chemosphere 51 (7), 577-584.

Coutinho, J. A. P., Andersen, S. I., Stenby, E. H., 1995. Evaluation of activity coefficient models in prediction of alkane solid-liquid equilibria. Fluid Phase Equilibr. 103, 23-39.

Dodson, R. E., Camann, D. E., Morello-Frosch, R., Brody, J. G., Rudel, R. A., 2015. Semivolatile organic compounds in homes: strategies for efficient and systematic exposure measurement based on empirical and theoretical factors. Environ. Sci. Technol. 49 (1), 113-122.

Domanska, U., Paduszynski, K., 2010. Gas-liquid chromatography measurements of activity coefficients at infinite dilution of various organic solutes and water in tri-isobutylmethylphosphonium tosylate ionic liquid. J. Chem. Thermodyn. 42 (6), 707-711. 
Finizio, A., Mackay, D., Bidleman, T., Harner, T., 1997. Octanol-air partition coefficient as a predictor of partitioning of semi-volatile organic chemicals to aerosols. Atmos. Environ. 31 (15), 2289-2296.

Finlayson-Pitts, B. J., Pitts, Jr. J. N. Chemistry of the upper and lower atmosphere. San Diego: Academic Press; 2000.

Fournier K., Glorennec, P., Bonvallot, N., 2014. An exposure-based framework for grouping pollutants for a cumulative risk assessment approach: case study of indoor semi-volatile organic compounds. Environ. Res. 130, 20-28.

Fredenslund, A., Jones, R. L., Prausnitz, J. M., 1975. Group-contribution estimation of activity coefficients in nonideal liquid mixtures. AICHE J. 21 (6), 1086-1099.

Harner, T., 1998. Octanol-air partition coefficient for describing particle/gas partitioning of aromatic compounds in urban air. Environ. Sci. Technol. 32, 1494-1502.

Harner, T., Bidleman, T. F., 1996. Measurements of octanol-air partition coefficients for polychlorinated biphenyls. J. Chem. Eng. Data 41 (4), 895-899.

Harner, T., Bidleman, T. F., 1998. Measurement of octanol-air partition coefficients for polycyclic aromatic hydrocarbons and polychlorinated naphthalenes. J. Chem. Eng. Data 43 (1), 40-46.

Harner, T., Mackay, D., 1995. Measurement of octanol-air partition coefficients for chlorobenzenes, PCBs, and DDT. Environ. Sci. Technol. 29 (6), 1599-1606. 
He, J., Balasubramanian, R., 2009. A study of gas/particle partitioning of SVOCs in the tropical atmosphere of Southeast Asia. Atmos. Environ. 43 (29), 4375-4383.

Husar, R. B., Shu, W. R., 1975. Thermal analyses of Los-Angeles smog aerosol. J. Appl. Meteorol. 14 (8), 1558-1565.

Jang, M., Kamens, R. M., 1998. A thermodynamic approach for modeling partitioning of semivolatile organic compounds on atmospheric particulate matter: humidity effects. Environ. Sci. Technol. 32 (9), 1237-1243.

Kato, R., Gmehling, J., 2005. Systems with ionic liquids: measurement of VLE and $\gamma^{\infty}$ data and prediction of their thermodynamic behavior using original UNIFAC, mod. UNIFAC(Do) and COSMO-RS(Ol). J. Chem. Thermodyn. 37 (6), 603-619.

Kaupp, H., McLachlan, M. S., 1999. Gas/particle partitioning of PCDD/Fs, PCBs, PCNs and PAHs. Chemosphere 38 (14), 3411-3421.

Li, X. H., Chen, J. W., Zhang, L., Qiao, X. L., Huang, L. P., 2006. The fragment constant method for predicting octanol-air partition coefficients of persistent organic pollutants at different temperatures. J. Phys. Chem. Ref. Data 35 (3), 1365-1384.

Liu, C., Shi, S. S., Weschler, C. J., Zhao, B., Zhang, Y. P., 2013. Analysis of the dynamic interaction between SVOCs and airborne particles. Aerosol Sci. Technol. 47 (2), 125-136.

Lohmann, R., Lammel, G., 2004. Adsorptive and Absorptive Contributions to the Gas-Particle Partitioning of Polycyclic Aromatic Hydrocarbons: State of Knowledge and Recommended Parametrization for Modeling. Environ. Sci. Technol. 38, 3793-3803. 
Naumova, Y.Y., Offenberg, J.H., Eisenreich, S.J., Meng, Q.Y., Polidori, A. Turpin, B.J., Weisel, C.P., Morandi, M.T., Colome, S.D., Stock, T.H., Winer, A.M., Alimokhtari, S., Kwon, J., Maberti, S., Shendell, D., Jones, J., Farrar, C., 2003. Gas/particle distribution of polycyclic aromatic hydrocarbons in coupled outdoor/indoor atmospheres. Atmos. Environ. 37 (5), 703719.

Odabasi, M., Cetin, B., 2012. Determination of octanol-air partition coefficients of organochlorine pesticides (OCPs) as a function of temperature: application to air-soil exchange. J. Environ. Manage. 113, 432-439.

Odabasi, M., Cetina, E.; Sofuoglu, A., 2006a. Determination of octanol-air partition coefficients and supercooled liquid vapor pressures of PAHs as a function of temperature: application to gasparticle partitioning in an urban atmosphere. Atmos. Environ. 40 (34), 6615-6625.

Odabasi, M., Cetin, B., Sofuoglu, A., 2006b. Henry's law constant, octanol-air partition coefficient and supercooled liquid vapor pressure of carbazole as a function of temperature: application to gas/particle partitioning in the atmosphere. Chemosphere 62 (7), 1087-1096.

Pankow, J. F., 1994. An absorption model of gas/particle partitioning of organic compounds in the atmosphere. Atmos. Environ. 28 (2), 185-188.

Pankow, J. F., 1987. Review and comparative analysis of the theories on partitioning between the gas and aerosol particulate phases in the atmosphere. Atmos. Environ. 21 (11), 2275-2283.

Rudel, R. A., Camann, D. E., Spengler, J. D., Korn, L. R., Brody, J. G., 2003. Phthalates, alkylphenols, pesticides, polybrominated diphenyl ethers, and other endocrine-disrupting compounds in indoor air and dust. Environ. Sci. Technol. 37 (20), 4543-4553. 
Salapasidou, M., Samara, C., Voutsa, D., 2011. Endocrine disrupting compounds in the atmosphere of the urban area of Thessaloniki, Greece. Atmos. Environ. 45 (22), 3720-3729.

Schwarzenbach, R. P., Gschwend, P. M., Imboden, D. M. Environmental organic chemistry. 2nd ed. New Jersey: John Wiley \& Sons, Inc; 2003.

Seinfeld, J. H., Pandis, S. N. Atmospheric chemistry and physics. New York: John Wiley \& Sons; 2006.

Shoeib, M., Harner, T., 2002. Using measured octanol-air partition coefficients to explain environmental partitioning of organochlorine pesticides. Environ. Toxicol. Chem. 21 (5), 984990.

United States Environmental Protection Agency Website, http://www2.epa.gov/tsca-screeningtools/download-epi-suitetm-estimation-program-interface-v411.

Weschler, C. J., Nazaroff, W. W., 2008. Semivolatile organic compounds in indoor environments. Atmos. Environ. 42 (40), 9018-9040.

Weschler, C. J., Nazaroff, W. W., 2010. SVOC partitioning between the gas phase and settled dust indoors. Atmos. Environ. 44 (30), 3609-3620.

Weschler, C. J., Salthammer, T., Fromme, H., 2008. Partitioning of phthalates among the gas phase, airborne particles and settled dust in indoor environments. Atmos. Environ. 42 (7), 14491460.

Won, K. W., 1989. Thermodynamic calculation of cloud point temperatures and wax phase compositions of refined hydrocarbon mixtures. Fluid Phase Equilibr. 53, 377-396. 
Xu, S. H., Kropscott, B., 2013. Octanol/air partition coefficients of volatile methylsiloxanes and their temperature dependence. J. Chem. Eng. Data 58 (1), 136-142. 


\section{TABLES}

Table 1. Comparison of the predicted and observed values of $K_{\mathrm{p}}$.

\begin{tabular}{|c|c|c|c|c|c|c|c|c|}
\hline \multirow[t]{3}{*}{ Pollutant } & \multicolumn{8}{|c|}{ Temperature $\left({ }^{\circ} \mathrm{C}\right)$} \\
\hline & \multicolumn{2}{|c|}{10} & \multicolumn{2}{|c|}{20} & \multicolumn{2}{|c|}{30} & \multicolumn{2}{|c|}{40} \\
\hline & $\begin{array}{c}K_{\mathrm{p}} \\
\text { predicted } \\
\left(\mathrm{m}^{3} / \mu \mathrm{g}\right)\end{array}$ & $\begin{array}{c}K_{\mathrm{p}} \\
\text { observed* }^{*} \\
\left(\mathrm{~m}^{3} / \mu \mathrm{g}\right)\end{array}$ & $\begin{array}{c}K_{\mathrm{p}} \\
\text { predicted } \\
\left(\mathrm{m}^{3} / \mu \mathrm{g}\right)\end{array}$ & $\begin{array}{c}K_{\mathrm{p}} \\
\text { observed* }^{*} \\
\left(\mathrm{~m}^{3} / \mu \mathrm{g}\right)\end{array}$ & $\begin{array}{c}K_{\mathrm{p}} \\
\text { predicted } \\
\left(\mathrm{m}^{3} / \mu \mathrm{g}\right)\end{array}$ & $\begin{array}{c}K_{\mathrm{p}} \\
\text { observed* }^{*} \\
\left(\mathrm{~m}^{3} / \mu \mathrm{g}\right)\end{array}$ & $\begin{array}{c}K_{\mathrm{p}} \\
\text { predicted } \\
\left(\mathrm{m}^{3} / \mu \mathrm{g}\right)\end{array}$ & $\begin{array}{c}K_{\mathrm{p}} \\
\text { observed }^{*} \\
\left(\mathrm{~m}^{3} / \mu \mathrm{g}\right)\end{array}$ \\
\hline \multicolumn{9}{|l|}{ PCNs } \\
\hline 1-Chloronaphthalene & $1.07 \times 10^{-6}$ & $9.82 \times 10^{-7}$ & - & - & $2.50 \times 10^{-7}$ & $1.32 \times 10^{-7}$ & $1.30 \times 10^{-7}$ & $7.98 \times 10^{-8}$ \\
\hline 1,2-Dichloronaphthalene & $9.53 \times 10^{-6}$ & $8.95 \times 10^{-6}$ & - & - & $1.86 \times 10^{-6}$ & $1.10 \times 10^{-6}$ & $8.90 \times 10^{-7}$ & $5.40 \times 10^{-7}$ \\
\hline 1,2,3-Trichloronaphthalene & $7.33 \times 10^{-5}$ & $6.95 \times 10^{-5}$ & - & - & $1.17 \times 10^{-5}$ & $7.98 \times 10^{-6}$ & $5.09 \times 10^{-6}$ & $3.25 \times 10^{-6}$ \\
\hline $1,2,3,4-$ & $4.34 \times 10^{-4}$ & $4.29 \times 10^{-4}$ & - & - & $5.97 \times 10^{-5}$ & $4.49 \times 10^{-5}$ & $2.44 \times 10^{-5}$ & $1.56 \times 10^{-5}$ \\
\hline \multicolumn{9}{|l|}{ Tetrachloronaphthalene } \\
\hline $1,2,3,6,7-$ & $2.74 \times 10^{-3}$ & $2.97 \times 10^{-3}$ & - & - & $3.77 \times 10^{-4}$ & $2.83 \times 10^{-4}$ & $1.54 \times 10^{-4}$ & $8.36 \times 10^{-5}$ \\
\hline \multicolumn{9}{|l|}{ Pentachloronaphthalene } \\
\hline $1,2,3,4,6,7-$ & $1.36 \times 10^{-2}$ & $1.51 \times 10^{-2}$ & - & - & $1.36 \times 10^{-3}$ & $1.16 \times 10^{-3}$ & $4.80 \times 10^{-4}$ & $2.75 \times 10^{-4}$ \\
\hline \multicolumn{9}{|l|}{ Hexachloronaphthalene } \\
\hline $1,2,3,4,5,6,7-$ & $1.31 \times 10^{-1}$ & $1.32 \times 10^{-1}$ & - & - & $1.10 \times 10^{-2}$ & $1.11 \times 10^{-2}$ & $3.62 \times 10^{-3}$ & $2.25 \times 10^{-3}$ \\
\hline
\end{tabular}




\begin{tabular}{|c|c|c|c|c|c|c|c|c|}
\hline \multirow[t]{3}{*}{ Pollutant } & \multicolumn{8}{|c|}{ Temperature $\left({ }^{\circ} \mathrm{C}\right)$} \\
\hline & \multicolumn{2}{|c|}{10} & \multicolumn{2}{|c|}{20} & \multicolumn{2}{|c|}{30} & \multicolumn{2}{|c|}{40} \\
\hline & $\begin{array}{c}K_{\mathrm{p}} \\
\text { predicted } \\
\left(\mathrm{m}^{3} / \mu \mathrm{g}\right)\end{array}$ & $\begin{array}{c}K_{\mathrm{p}} \\
\text { observed }^{*} \\
\left(\mathrm{~m}^{3} / \mu \mathrm{g}\right)\end{array}$ & $\begin{array}{c}K_{\mathrm{p}} \\
\text { predicted } \\
\left(\mathrm{m}^{3} / \mu \mathrm{g}\right)\end{array}$ & $\begin{array}{c}K_{\mathrm{p}} \\
\text { observed }^{*} \\
\left(\mathrm{~m}^{3} / \mu \mathrm{g}\right)\end{array}$ & $\begin{array}{c}K_{\mathrm{p}} \\
\text { predicted } \\
\left(\mathrm{m}^{3} / \mu \mathrm{g}\right)\end{array}$ & $\begin{array}{c}K_{\mathrm{p}} \\
\text { observed }^{*} \\
\left(\mathrm{~m}^{3} / \mu \mathrm{g}\right)\end{array}$ & $\begin{array}{c}K_{\mathrm{p}} \\
\text { predicted } \\
\left(\mathrm{m}^{3} / \mu \mathrm{g}\right)\end{array}$ & $\begin{array}{c}K_{\mathrm{p}} \\
\text { observed }^{*} \\
\left(\mathrm{~m}^{3} / \mu \mathrm{g}\right)\end{array}$ \\
\hline \multicolumn{9}{|c|}{ Heptachloronaphthalene } \\
\hline \multicolumn{9}{|l|}{ PCBs } \\
\hline 3 & $1.06 \times 10^{-5}$ & $1.08 \times 10^{-5}$ & - & - & $1.69 \times 10^{-6}$ & $1.67 \times 10^{-6}$ & - & - \\
\hline 53 & $2.01 \times 10^{-4}$ & $2.00 \times 10^{-4}$ & - & - & $2.47 \times 10^{-5}$ & $2.77 \times 10^{-5}$ & - & - \\
\hline 66 & $2.15 \times 10^{-3}$ & $1.79 \times 10^{-3}$ & - & - & $2.22 \times 10^{-4}$ & $2.64 \times 10^{-4}$ & - & - \\
\hline 77 & $1.25 \times 10^{-2}$ & $0.92 \times 10^{-2}$ & - & - & $1.16 \times 10^{-3}$ & $1.18 \times 10^{-3}$ & - & - \\
\hline 95 & $1.69 \times 10^{-3}$ & $1.29 \times 10^{-3}$ & - & - & $1.36 \times 10^{-4}$ & $1.42 \times 10^{-4}$ & - & - \\
\hline 96 & $8.34 \times 10^{-4}$ & $6.64 \times 10^{-4}$ & - & - & $7.24 \times 10^{-5}$ & $7.98 \times 10^{-5}$ & - & - \\
\hline 101 & $2.65 \times 10^{-3}$ & $2.41 \times 10^{-3}$ & - & - & $2.72 \times 10^{-4}$ & $2.41 \times 10^{-4}$ & - & - \\
\hline 105 & $2.70 \times 10^{-2}$ & $2.77 \times 10^{-2}$ & - & - & $2.24 \times 10^{-3}$ & $2.36 \times 10^{-3}$ & - & - \\
\hline 118 & $1.70 \times 10^{-2}$ & $1.75 \times 10^{-2}$ & - & - & $1.48 \times 10^{-3}$ & $1.49 \times 10^{-3}$ & - & - \\
\hline 138 & $1.80 \times 10^{-2}$ & $1.63 \times 10^{-2}$ & - & - & $1.47 \times 10^{-3}$ & $1.36 \times 10^{-3}$ & - & - \\
\hline 153 & $1.90 \times 10^{-2}$ & $1.67 \times 10^{-2}$ & - & - & $1.12 \times 10^{-3}$ & $9.82 \times 10^{-4}$ & - & - \\
\hline
\end{tabular}




\begin{tabular}{|c|c|c|c|c|c|c|c|c|}
\hline \multirow[t]{3}{*}{ Pollutant } & \multicolumn{8}{|c|}{ Temperature $\left({ }^{\circ} \mathrm{C}\right)$} \\
\hline & \multicolumn{2}{|c|}{10} & \multicolumn{2}{|c|}{20} & \multicolumn{2}{|c|}{30} & \multicolumn{2}{|c|}{40} \\
\hline & $\begin{array}{c}K_{\mathrm{p}} \\
\text { predicted } \\
\left(\mathrm{m}^{3} / \mu \mathrm{g}\right)\end{array}$ & $\begin{array}{c}K_{\mathrm{p}} \\
\text { observed }^{*} \\
\left(\mathrm{~m}^{3} / \mu \mathrm{g}\right)\end{array}$ & $\begin{array}{c}K_{\mathrm{p}} \\
\text { predicted } \\
\left(\mathrm{m}^{3} / \mu \mathrm{g}\right)\end{array}$ & $\begin{array}{c}K_{\mathrm{p}} \\
\text { observed }^{*} \\
\left(\mathrm{~m}^{3} / \mu \mathrm{g}\right)\end{array}$ & $\begin{array}{c}K_{\mathrm{p}} \\
\text { predicted } \\
\left(\mathrm{m}^{3} / \mu \mathrm{g}\right)\end{array}$ & $\begin{array}{c}K_{\mathrm{p}} \\
\text { observed* }^{*} \\
\left(\mathrm{~m}^{3} / \mu \mathrm{g}\right)\end{array}$ & $\begin{array}{c}K_{\mathrm{p}} \\
\text { predicted } \\
\left(\mathrm{m}^{3} / \mu \mathrm{g}\right)\end{array}$ & $\begin{array}{c}K_{\mathrm{p}} \\
\text { observed }^{*} \\
\left(\mathrm{~m}^{3} / \mu \mathrm{g}\right)\end{array}$ \\
\hline 171 & $5.02 \times 10^{-2}$ & $5.52 \times 10^{-2}$ & - & - & $3.65 \times 10^{-3}$ & $3.65 \times 10^{-3}$ & - & - \\
\hline
\end{tabular}

Dioxins and furans

2,3,7-

$6.29 \times 10^{-3} \quad 2.62 \times 10^{-3}$

$1.21 \times 10^{-3} \quad 8.22 \times 10^{-4}$

$2.59 \times 10^{-4} \quad 3.44 \times 10^{-4}$

$6.13 \times 10^{-5} \quad 1.26 \times 10^{-4}$

Trichlorodibenzodioxin

$2,3,7,8-$

$4.11 \times 10^{-2} \quad 2.70 \times 10^{-2}$

$1.59 \times 10^{-3} \quad 2.04 \times 10^{-3}$

$3.65 \times 10^{-4} \quad 8.91 \times 10^{-4}$

Tetrachlorodibenzofuran

$1,2,3,7,8-$

Pentachlorodibenzodioxin

\section{$1,2,3,4,7,8$}

Hexachlorodibenzodioxin
$3.46 \times 10^{-2} \quad 2.94 \times 10^{-2}$

$1.23 \times 10^{-1} \quad 1.01 \times 10^{-1}$
$1.38 \times 10^{-3} \quad 2.28 \times 10^{-3}$

$4.51 \times 10^{-3} \quad 7.93 \times 10^{-3}$ 


\begin{tabular}{|c|c|c|c|c|c|c|c|c|}
\hline \multirow[t]{3}{*}{ Pollutant } & \multicolumn{8}{|c|}{ Temperature $\left({ }^{\circ} \mathrm{C}\right)$} \\
\hline & \multicolumn{2}{|c|}{10} & \multicolumn{2}{|c|}{20} & \multicolumn{2}{|c|}{30} & \multicolumn{2}{|c|}{40} \\
\hline & $\begin{array}{c}K_{\mathrm{p}} \\
\text { predicted } \\
\left(\mathrm{m}^{3} / \mu \mathrm{g}\right)\end{array}$ & $\begin{array}{c}K_{\mathrm{p}} \\
\text { observed }^{*} \\
\left(\mathrm{~m}^{3} / \mu \mathrm{g}\right)\end{array}$ & $\begin{array}{c}K_{\mathrm{p}} \\
\text { predicted } \\
\left(\mathrm{m}^{3} / \mu \mathrm{g}\right)\end{array}$ & $\begin{array}{c}K_{\mathrm{p}} \\
\text { observed }^{*} \\
\left(\mathrm{~m}^{3} / \mu \mathrm{g}\right)\end{array}$ & $\begin{array}{c}K_{\mathrm{p}} \\
\text { predicted } \\
\left(\mathrm{m}^{3} / \mu \mathrm{g}\right)\end{array}$ & $\begin{array}{c}K_{\mathrm{p}} \\
\text { observed }^{*} \\
\left(\mathrm{~m}^{3} / \mu \mathrm{g}\right)\end{array}$ & $\begin{array}{c}K_{\mathrm{p}} \\
\text { predicted } \\
\left(\mathrm{m}^{3} / \mu \mathrm{g}\right)\end{array}$ & $\begin{array}{c}K_{\mathrm{p}} \\
\text { observed }^{*} \\
\left(\mathrm{~m}^{3} / \mu \mathrm{g}\right)\end{array}$ \\
\hline $1,2,3,4,6,7,8$ & - & - & $2.79 \times 10^{-1}$ & $1.83 \times 10^{-1}$ & - & - & $6.80 \times 10^{-3}$ & $2.38 \times 10^{-2}$ \\
\hline
\end{tabular}

Heptachlorodibenzodioxin

\begin{tabular}{|c|c|c|c|c|c|c|c|c|}
\hline PBDEs & & & & & & & & \\
\hline 28 & $8.04 \times 10^{-3}$ & $6.27 \times 10^{-3}$ & - & - & $6.16 \times 10^{-4}$ & $7.78 \times 10^{-4}$ & $1.93 \times 10^{-4}$ & $3.03 \times 10^{-4}$ \\
\hline 66 & $1.66 \times 10^{-1}$ & $2.60 \times 10^{-1}$ & $4.44 \times 10^{-2}$ & $5.53 \times 10^{-2}$ & $1.29 \times 10^{-2}$ & $1.31 \times 10^{-2}$ & $4.09 \times 10^{-3}$ & $3.37 \times 10^{-3}$ \\
\hline 100 & $4.82 \times 10^{-1}$ & $5.04 \times 10^{-1}$ & $1.14 \times 10^{-1}$ & $1.11 \times 10^{-1}$ & $2.97 \times 10^{-2}$ & $2.69 \times 10^{-2}$ & $8.45 \times 10^{-3}$ & $7.16 \times 10^{-3}$ \\
\hline 153 & $2.75 \times 10^{0}$ & $2.15 \times 10^{0}$ & $5.98 \times 10^{-1}$ & $5.19 \times 10^{-1}$ & $1.44 \times 10^{-1}$ & $1.37 \times 10^{-1}$ & $3.80 \times 10^{-2}$ & $3.95 \times 10^{-2}$ \\
\hline \multicolumn{9}{|l|}{ PAHs } \\
\hline Fluorene & $1.71 \times 10^{-5}$ & $1.27 \times 10^{-5}$ & - & - & $1.84 \times 10^{-6}$ & $1.31 \times 10^{-6}$ & $6.75 \times 10^{-7}$ & $6.23 \times 10^{-7}$ \\
\hline Phenanthrene & $1.11 \times 10^{-4}$ & $7.40 \times 10^{-5}$ & - & - & $9.79 \times 10^{-6}$ & $1.05 \times 10^{-5}$ & $3.28 \times 10^{-6}$ & $3.37 \times 10^{-6}$ \\
\hline Pyrene & $2.11 \times 10^{-3}$ & $1.35 \times 10^{-3}$ & - & - & $1.69 \times 10^{-4}$ & $1.45 \times 10^{-4}$ & $5.42 \times 10^{-5}$ & $5.29 \times 10^{-5}$ \\
\hline
\end{tabular}




\begin{tabular}{|c|c|c|c|c|c|c|c|c|}
\hline \multirow[t]{3}{*}{ Pollutant } & \multicolumn{8}{|c|}{ Temperature $\left({ }^{\circ} \mathrm{C}\right)$} \\
\hline & \multicolumn{2}{|c|}{10} & \multicolumn{2}{|c|}{20} & \multicolumn{2}{|c|}{30} & \multicolumn{2}{|c|}{40} \\
\hline & $\begin{array}{c}K_{\mathrm{p}} \\
\text { predicted } \\
\left(\mathrm{m}^{3} / \mu \mathrm{g}\right)\end{array}$ & $\begin{array}{c}K_{\mathrm{p}} \\
\text { observed }^{*} \\
\left(\mathrm{~m}^{3} / \mu \mathrm{g}\right)\end{array}$ & $\begin{array}{c}K_{\mathrm{p}} \\
\text { predicted } \\
\left(\mathrm{m}^{3} / \mu \mathrm{g}\right)\end{array}$ & $\begin{array}{c}K_{\mathrm{p}} \\
\text { observed }^{*} \\
\left(\mathrm{~m}^{3} / \mu \mathrm{g}\right)\end{array}$ & $\begin{array}{c}K_{\mathrm{p}} \\
\text { predicted } \\
\left(\mathrm{m}^{3} / \mu \mathrm{g}\right)\end{array}$ & $\begin{array}{c}K_{\mathrm{p}} \\
\text { observed* }^{*} \\
\left(\mathrm{~m}^{3} / \mu \mathrm{g}\right)\end{array}$ & $\begin{array}{c}K_{\mathrm{p}} \\
\text { predicted } \\
\left(\mathrm{m}^{3} / \mu \mathrm{g}\right)\end{array}$ & $\begin{array}{c}K_{\mathrm{p}} \\
\text { observed* }^{*} \\
\left(\mathrm{~m}^{3} / \mu \mathrm{g}\right)\end{array}$ \\
\hline Fluoranthene & - & - & $5.62 \times 10^{-4}$ & $5.32 \times 10^{-4}$ & - & - & $6.17 \times 10^{-5}$ & $5.81 \times 10^{-5}$ \\
\hline
\end{tabular}

*Observed $K_{\mathrm{p}}$ values were derived from $K_{\mathrm{OA}}$ (Li et al., 2006). 


\section{Figures}



Fig. 1. Influence of the assumed $T_{\mathrm{e}}$ on the predicted value of $C_{\mathrm{g}}^{*}$ 


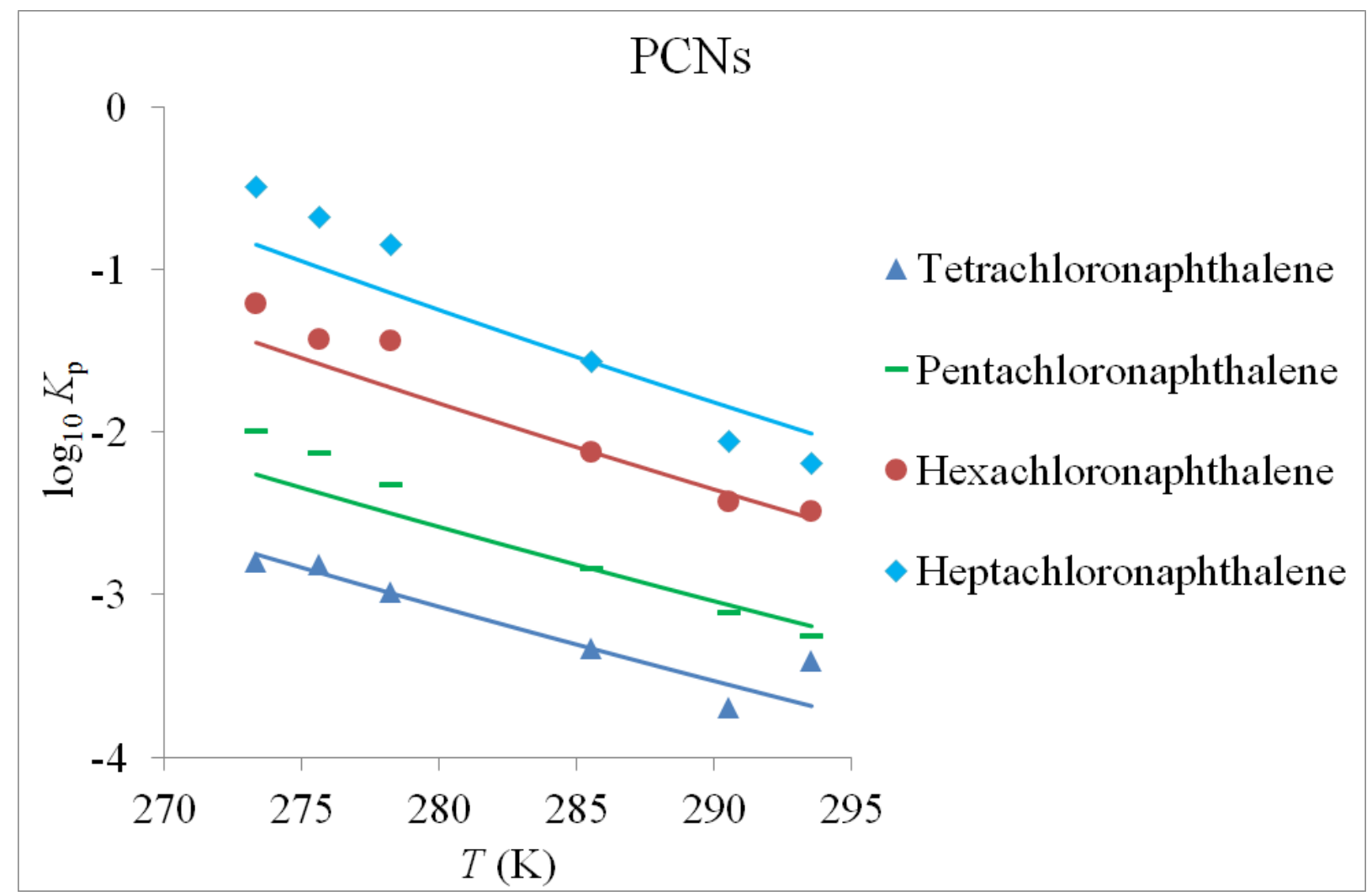

(a) 




(b) 


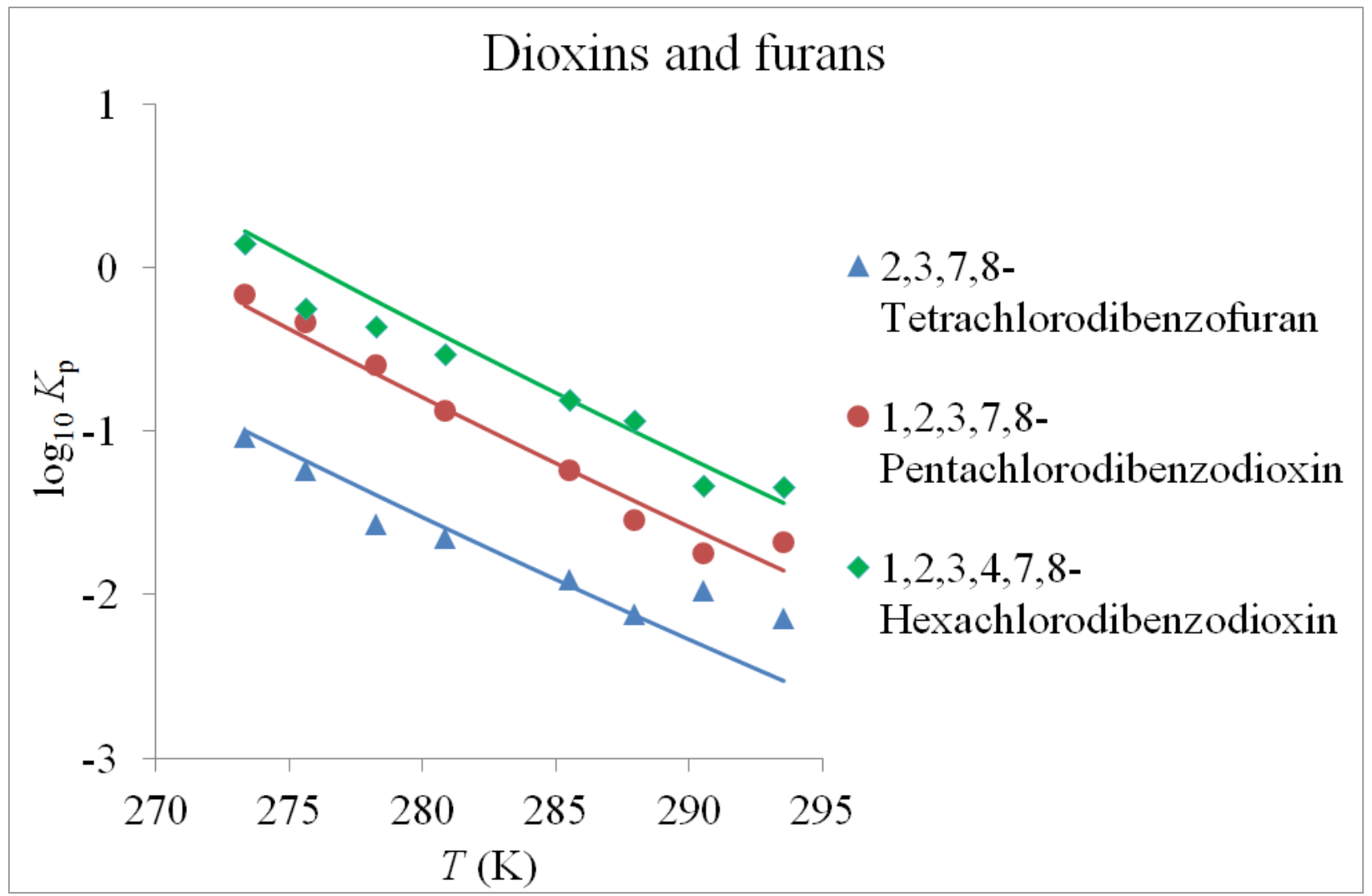

(c) 


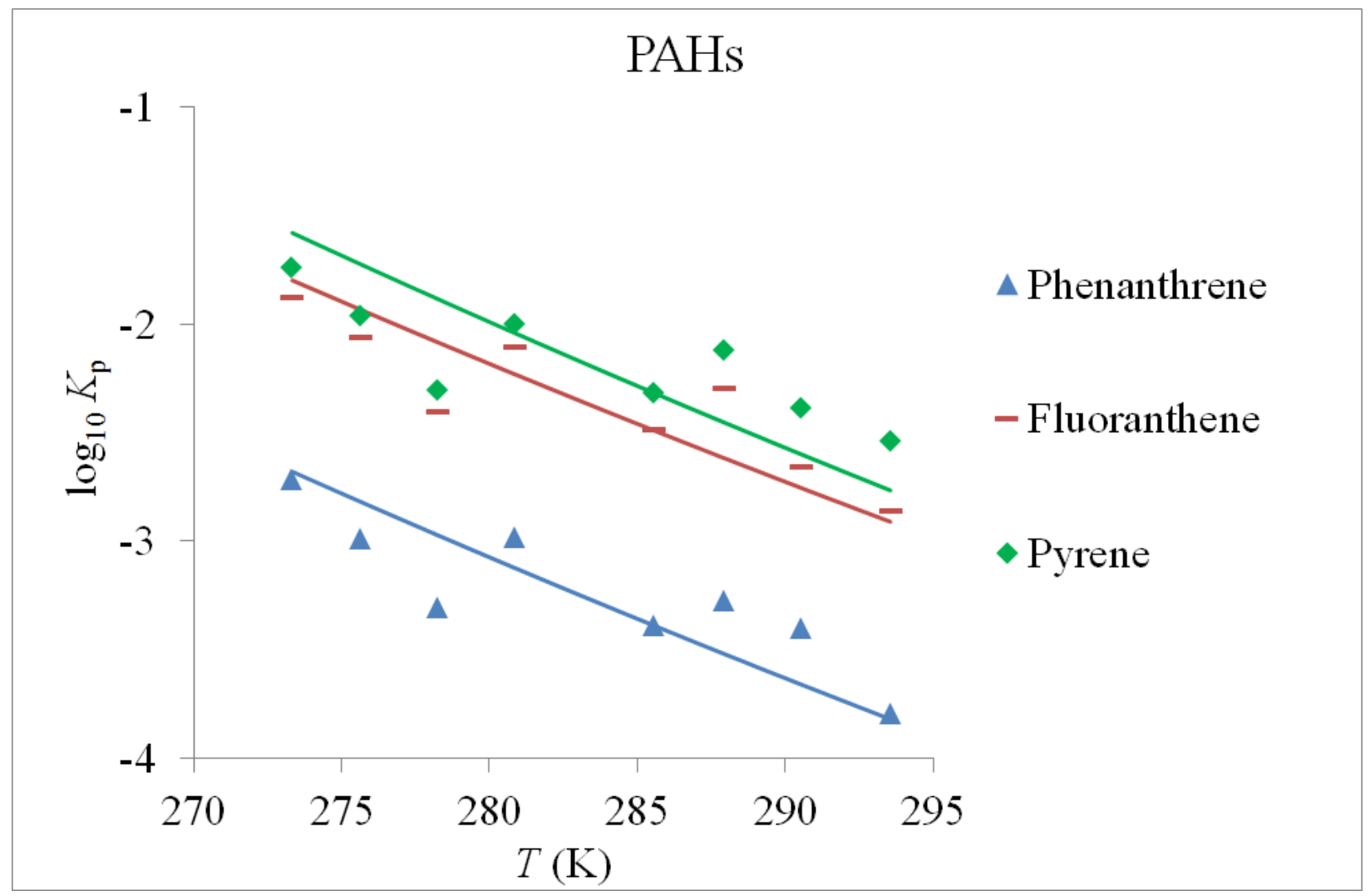

(d)

Fig. 2. Comparison of the predicted and measured values (Kaupp and McLachlan, 1999) of $\log _{10} K_{\mathrm{p}}$ at various temperatures (The predictions are presented in line while the measurements are presented in dots). 


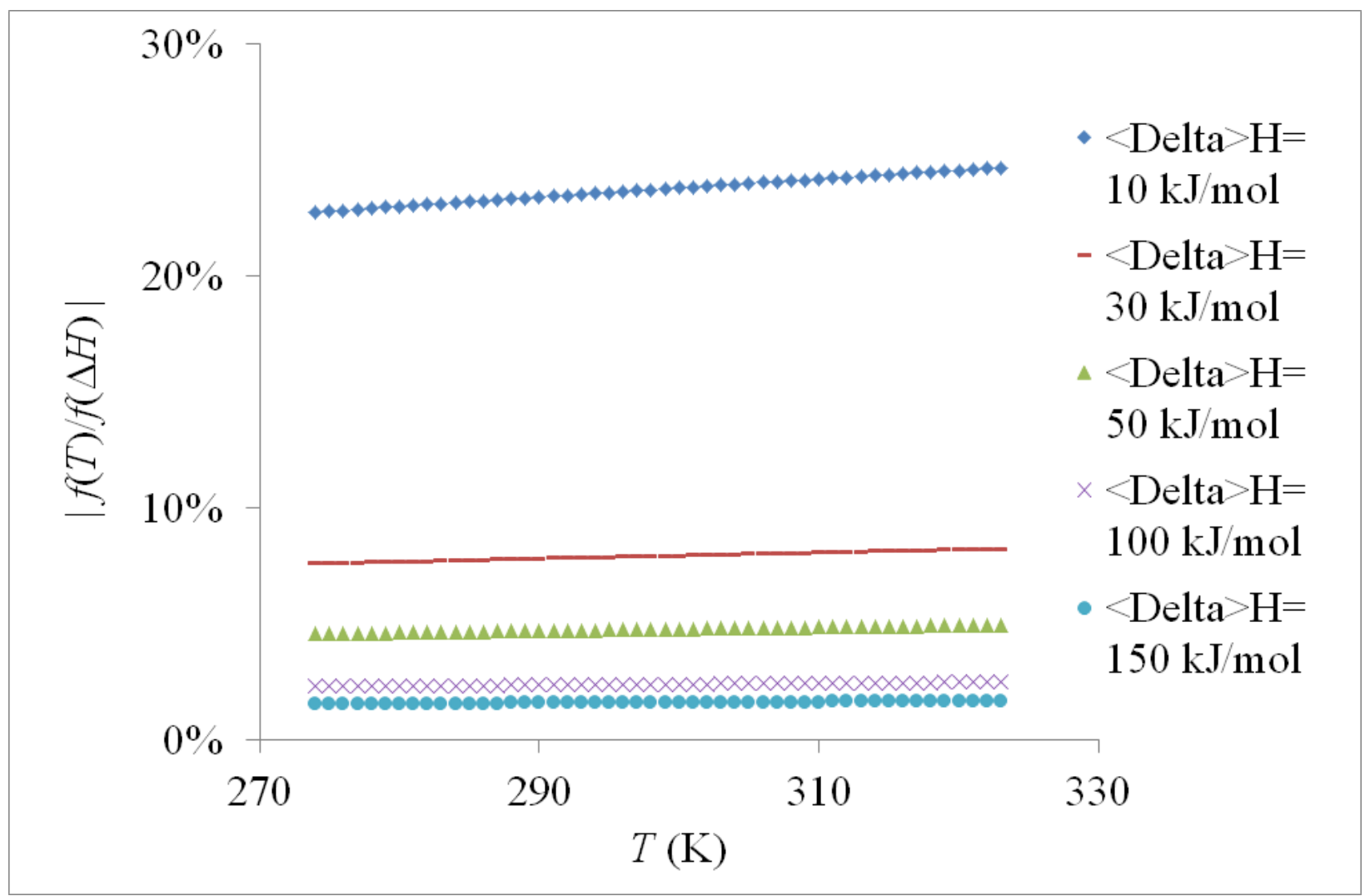

Fig. 3. $|f(T) / f(\Delta H)|$ at different temperatures and phase change enthalpies. 


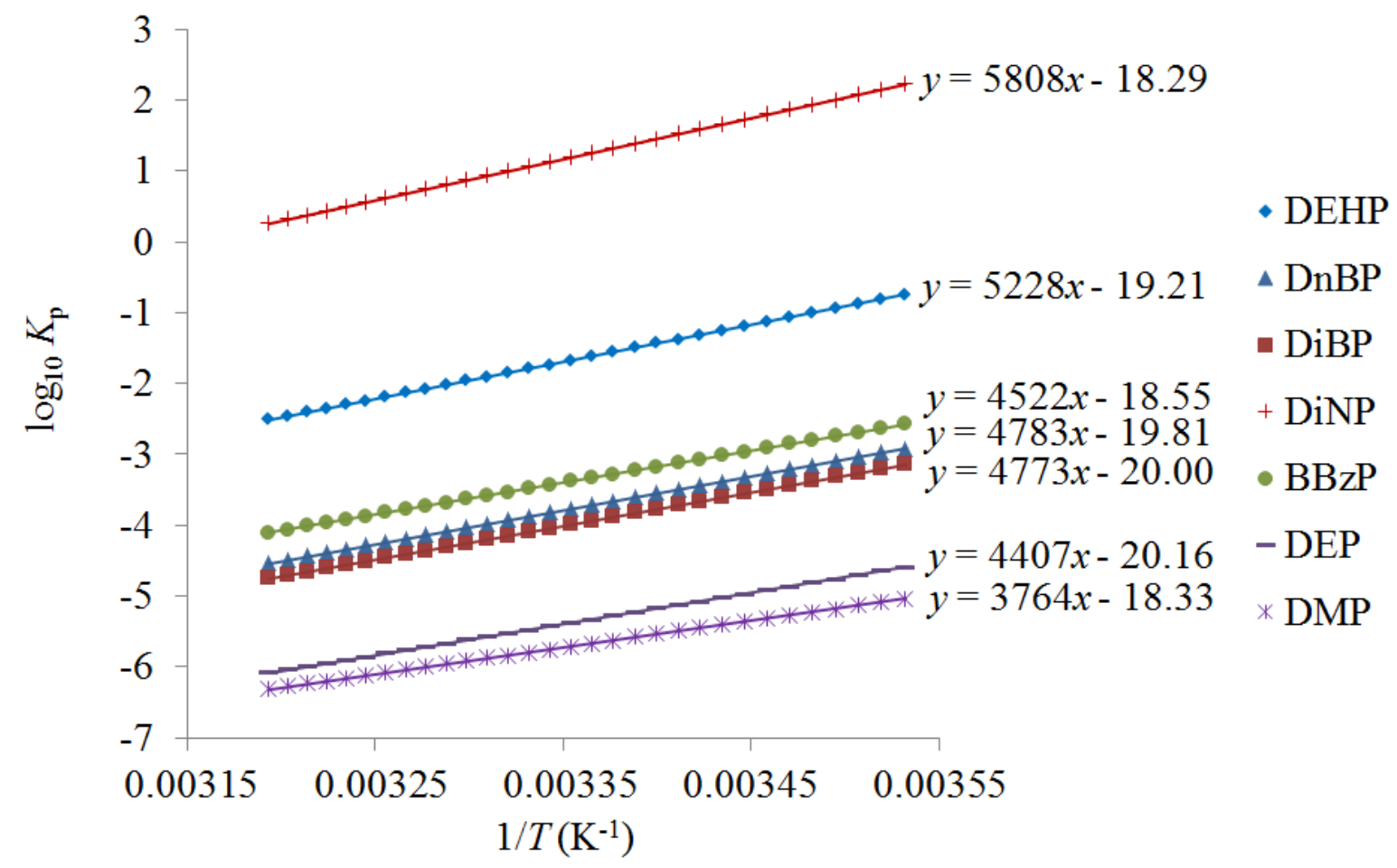

Fig. 4. $K_{\mathrm{p}}$ for phthalates. 


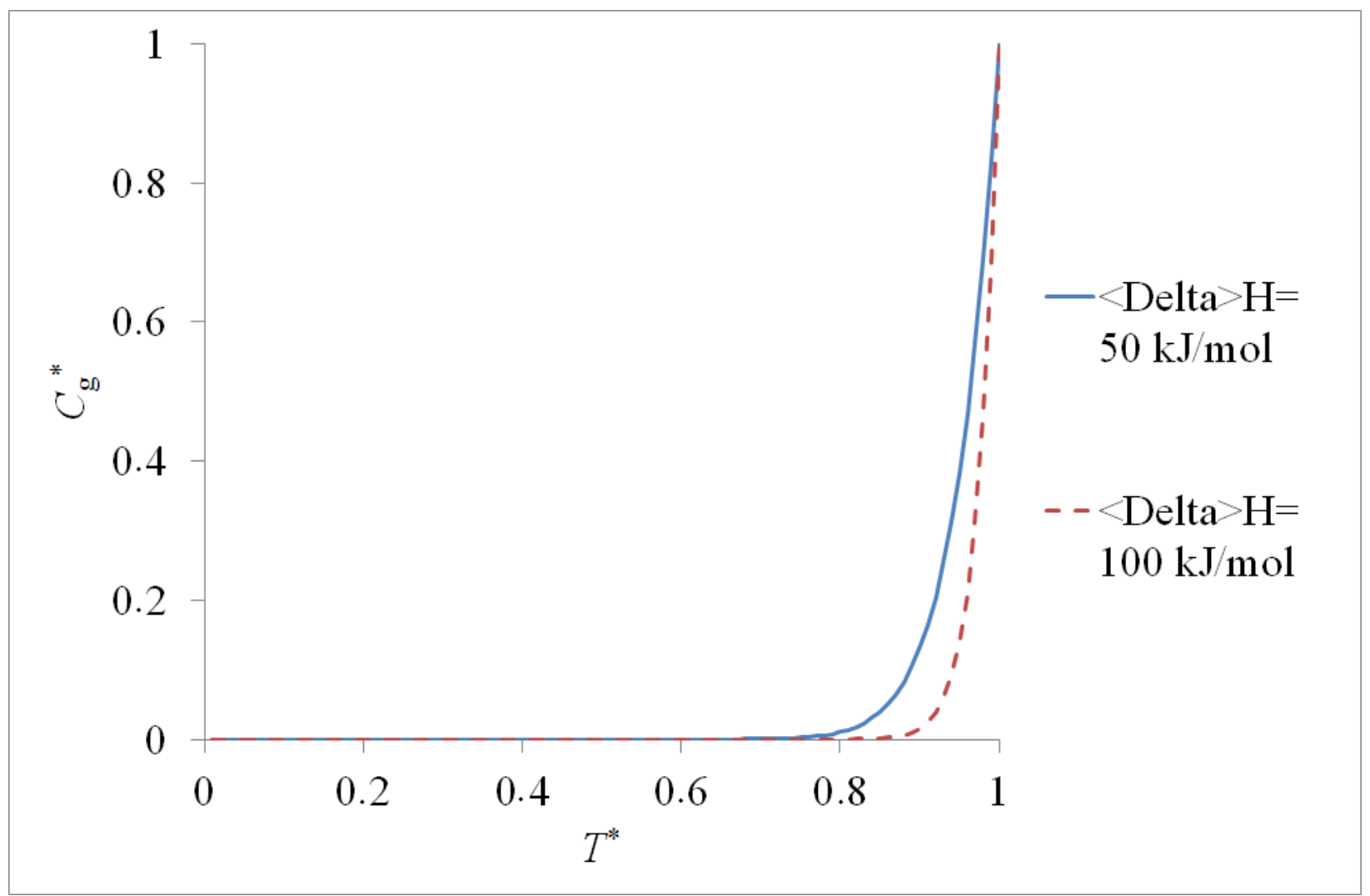

Fig. 5. Temperature dependence of the dimensionless gas-phase SVOC concentration. 


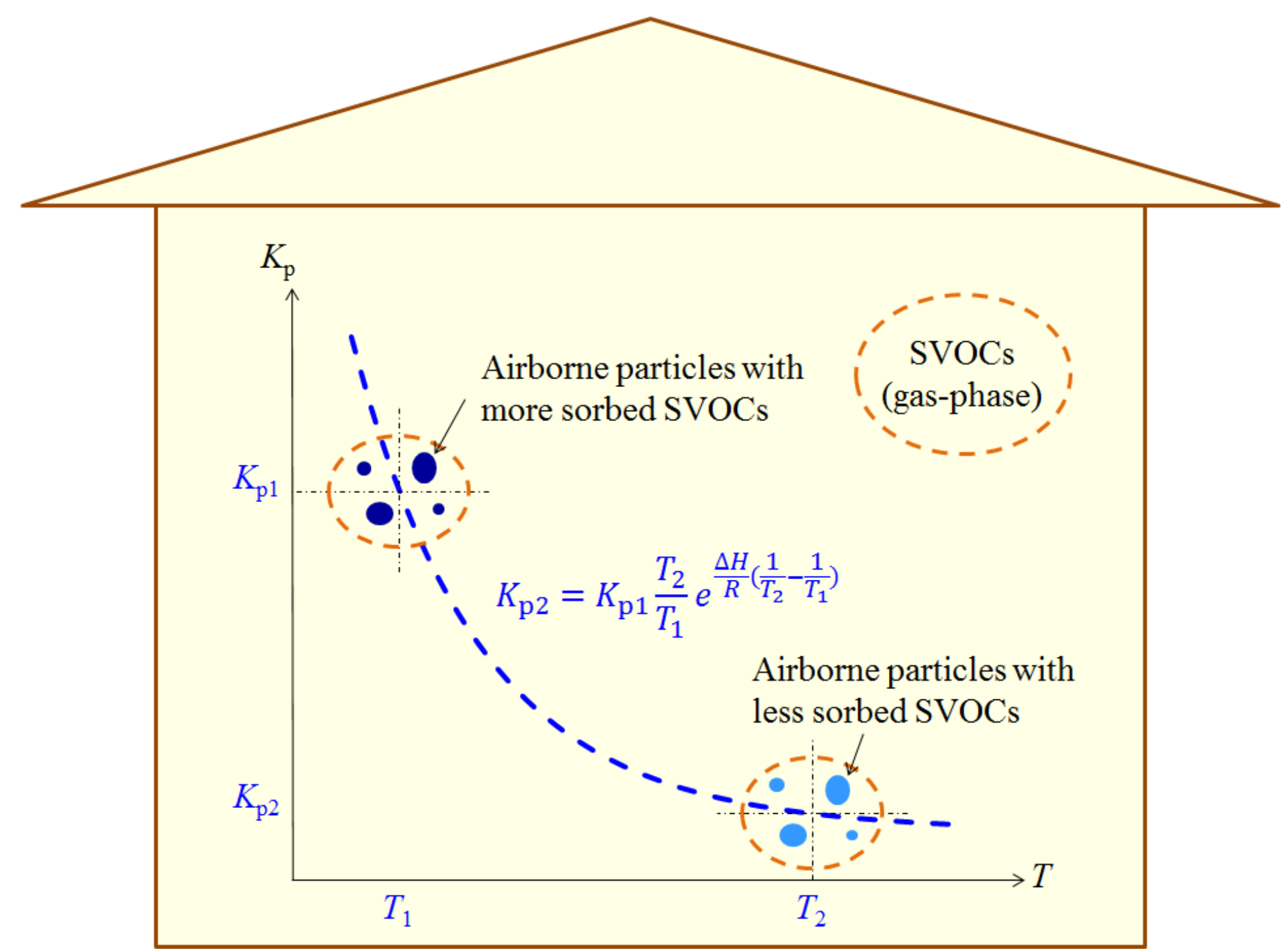

